\title{
PARADIGM SHIFT IN THE MICROFINANCE SECTOR AND ITS IMPLICATIONS FOR THEORY DEVELOPMENT: EMPIRICAL EVIDENCE FROM PAKISTAN
}

\author{
Dr Ashfaq Ahmad Khan', \\ University of Nizwa, Oman
}

\begin{abstract}
Financial and non-financial subsidized resources at the disposal of international donor agencies available for continued support of the microfinance sector are not unlimited. One of the strategies resorted to by the donor community to ensure supply of financial resources to the sector was to make it lucrative to private-sector investment. Thus, for more than a decade now, the donor community has been emphasizing profitability on the part of microfinance institutions to enable the sector to attract commercial capital. This move on the part of the donor community led microfinance institutions to adapt both functionally and structurally to better cope with donor's expectations and show them profits. Many microfinance institutions set example of successful adaptation and reorientation of their tangible and intangible organizational elements to enable them to survive under these new conditions. Laughlin's (1991) Model of Organizational Change provides a theoretical base for understanding such an organizational change in the light of changing external circumstances. While the Model placated all the relevant research questions, it did not fully explain all the trends observed in the empirical data collected for the study, which lent a room for development in the Model.
\end{abstract}

Key words: microfinance, organizational change, profitability, theory development.

\section{INTRODUCTION.}

\subsection{MICROFINANCE PARADIGM CHANGE.}

Keeping in view the amount of subsidized financial resources being poured into the sector and the limited success achieved in terms of poverty eradication around the world, a major portion of the literature on microfinance has been devoted to the performance related aspects of microfinance institutions particularly since the early 1990s (e.g., Remenyi and Quinones Jr. 2000, Conning 1999, Remenyi 1991, Hashemi et al 1996, Khandker 1996, Hulme and Mosley 1996a, Hulme and Mosley 1996b). The achievement of a good performance in terms of both return on investment and the number of poor households served on a sustainable basis reflect on the success of a microfinance institution. To ensure its survival in the long-run, a microfinance institution not only has to comply with the local rules and regulations applicable to its operations and meet society's expectations but also ensure the accomplishment of its primary objectives in terms of reaching highest possible number of poor households and eradicating poverty in its area of operations. By doing so, it demonstrates its legitimate existence to the society and also proves itself to be a legitimate recipient of financial and nonfinancial resources allocated to the sector (Snow 1999).

\footnotetext{
${ }^{1}$ Assistant Professor at the University of Nizwa in Oman Email: ashfaq@unizwa.edu.om
} 
Subsidized financial resources are not unlimited. International donor community found it beyond their means to keep on providing subsidized financial resources to MFIs to ensure their survival in the long run. Emphasis on self-sustainability on the part of donors was initiated and expanded upon during the period from early to the mid-1990s (Robinson 2001 and 2002, Fernando 2006, Yaron 1994, Baydas et al 1997, CGAP 1996, Chaves and Gonzalez-Vega 1996, Gonzalez-Vega and Schreiner 1997, Dichter 1996, Rogaly 1996), and has given a new direction to the practices of microfinance players around the world. According to the CGAP (1997) all microfinance institutions have to depict two kinds of selfsustainability before claiming to be self-sustainable: first, the 'operational self-sufficiency' wherein all MFIs are required to depict full coverage of all their operational and administrative costs, including losses from bad loans, from their revenues from operations, and second the 'financial self-sufficiency', wherein all microfinance institutions have to prove that they are meeting all their financing requirements through funds generated from internal operations and other commercial sources, and covering all their financing costs. Thus, MFIs not only have to cover all their costs but also provide for their financing needs from their own operations without depending on help from outside entity. In addition, these institutions must treat all funds at their disposal as commercial funds with a cost to investors (CGAP 1997, Edgcomb and Cawley 1994, p. 86). The CGAP, however, concedes that in practice few microfinance institutions fulfil these conditions to be eligible for being treated as fully selfsustainable (CGAP 1997).

This changed thinking and approach on the part of donors and the resultant competition among microfinance institutions for more business came as external environmental disturbances. Microfinance institutions throughout the world have to cope with this hostile external environment. Since microfinance is a general technique used by international donor community for fighting poverty at the world level, the donors' changed thinking and approach as to the sector's long-term survival and sustainability, as discussed above, simultaneously affected most of microfinance institutions around the world. The new microfinance paradigm has divided academicians into two major Schools of thought - the 'Welfarists' and the 'Institutionists'. Welfarists argue that the primary purpose of microfinance should be to help reduce poverty through subsidized credit. The idea they advocate is to ensure the inflow of subsidized financial resources to the sector on a continuing basis (e.g. Morduch 1998 and 1999). On the other hand, institutionists (e.g. Robinson 2001 and 2002) argues that the success of microfinance institutions both in terms of making a real dent on poverty through reaching a maximum number of poor households and ensuring their own long term survival and sustainability depend on their ability to adopt principles of commercialization in all their operations. Thus they want microfinance institutions to ensure their own long-term survival and sustainability through controlling costs and improving profitability instead of always expecting subsidized financial resources from the donor community for ensuring their longterm survival.

\subsection{THE MICROFINANCE SECTOR IN PAKISTAN.}

The idea of microfinance is not new in Pakistan. The origin of the government's efforts in the form of many subsidized microcredit ${ }^{2}$ services, particularly in the agriculture sector can be traced back to the 1960s. In addition, many Non-Governmental Organizations (NGOs) and

\footnotetext{
${ }^{2}$ The term 'microcredit', as opposed to 'microfinance', is deliberately used here to refer to the initial poverty eradication efforts when the sector was mainly dealing in small loans for the poor. The term 'microfinance' replaced the term 'microcredit' in the literature when the sector started providing a wide range of financial services to the poor in addition to extending small loans.
} 
financial institutions have been involved in providing these services in rural and urban areas for many years now. The Orangi Pilot Project (OPP) in Karachi and the Health and Nutrition Development Society (HANDS) in the Hyderabad and Thatta districts have been offering microfinance services for more than a decade (Rehman 2002). The initiation of a formal form of microfinance efforts was witnessed during the early 1980s when the Orangi Pilot Project (OPP) was established in the country's largest city, Karachi. This was followed by the launch of the Aga Khan Rural Support Program (AKRSP) as a private sector rural development program in 1982, which later on established itself as the most reputable microfinance model in Pakistan. When compared with the Non-Governmental Organizations sector, the AKRSP's microfinance wing accounts for around 70 percent of total microfinance coverage in the country in terms of number of poor households served (CGAP 2006, p.6).

Until the early 1990s, Pakistan's microfinance sector, as in most other countries, provided mainly microcredit services. In other words, the modus operandi of the microfinance providers was to secure subsidized financial resources from international donor agencies and extend cheap/subsidized loans in small amounts to poor households with a view to help them start a small business and thus change their social status. During the 1990s, with the paradigm shift in the sector, many NGOs began providing their poor clients with a variety of financial and non-financial services, not just microcredit. The 'Kashf Foundation' and the 'Asasah', present a picture of the sector's changed circumstances. These Non-governmental Organizations were established in the private sector in 1996 and 2003 respectively and operate under the new 'commercial microfinance' paradigm. Their focus is not only on providing a range of financial services to the country's poor but also on ensuring their own self-sustainability through a high emphasis on cost control and profitability in all aspects of their operations (CGAP 2006).

Pointing to the huge demand for microfinance services in the country, the Asian Development Bank's Microfinance Sector Development Review ${ }^{3}$ asserted that the potential demand for the services in terms of the number of poor households was approximately 6.5 million. The sector's services were in high demand while the supply was struggling to cope with the demand (ADB 2000, GoP 2003). According to the Pakistan Microfinance Network (PMN), as of June 2004, the total coverage of all the microfinance institutions was about 718,000 in terms of active microfinance clients. This was about 12 percent of the potential target of 6.5 million. These poor borrowers owed about US\$ 99 million in unpaid liabilities in respect of their loans (PMN 2004). This showed the number of unserved potential microfinance clients in the country and the need for concrete efforts to make microfinance a more effective tool to tackle the level of poverty in the country (CGAP 2006). However, there is a positive sign for the microfinance services providers in the country. In recent years Pakistan's rates of growth have been encouraging which may be expected to contribute positively to the effort of fighting poverty. The performance of Pakistan's economy has not been smooth over recent history. Noticeable variations can be observed in Pakistan's economic performance over the past decade. Pakistan's economic growth rate has not been encouraging during the 1990s with Gross Domestic Product (GDP) growth rate hovering around 3 percent per annum (GoP 2003). In recent years, however, the country's rates of growth have shown an encouraging trend. The average GDP growth rate was 4.0 percent over the five year period preceding fiscal year 2003-2004. The rate has risen steadily and exceeded 6 percent in 2003-2004 (USAID 2005, IMF 2005), and reached 8.6 percent in 2004-2005 (SPDC 2006). The average growth rate for the country's GDP remained stable around an average of 7 percent during the period

\footnotetext{
${ }^{3}$ Report and Recommendation of the President to the Board of Directors on the proposed loan to the Islamic Republic of Pakistan for the Microfinance Sector Development Program (November 2000).
} 
from 2003 to 2006 (PRSP 2006). The Social Policy and Development Centre (SPDC) annual review for the financial year 2005-2006 reveals that Pakistan's economic growth rate has slowed down to 6.6 percent in the financial year $2005-2006^{4}$ but was still encouraging keeping in view the slow GDP growth rate of below 4 percent in the recent past (SPDC 2006).

The elements of commercialism and self-sustainability in operations of most microfinance institutions in the country have helped them remarkably increase their outreach. While all microfinance programs in the country currently reach about one million poor households, the government's current poverty reduction strategy aims to cover an additional two million poor households by 2010. The current high recovery rate of outstanding loans among most of the country's microfinance institutions is also encouraging and point to their enhanced capacity of reaching more poor households in the future (APPC 2007).

\section{THE RESEARCH SITE.}

The changed thinking and approach of the donor community and the resulting consequences for the microfinance institutions, as discussed above, inspired this research, and the Aga Khan Rural Support Programme (AKRSP) $)^{5}$ was selected as a case. The AKRSP has been in operation in the northern part of Pakistan since its inception in 1982. It has been actively involved in providing microfinance services in the area through its Microfinance Division over these years. The reasons for choosing this MFI are: i) The AKRSP is pioneer in the field of microfinance in Pakistan (Hussein and Plateau 2003, Gloekler and Seeley 2003) and, ii) after experiencing the external environmental 'disturbances' during the 1990s, as discussed above, the AKRSP's Microfinance Division successfully adapted, reoriented, and subsequently transformed itself to the new environmental conditions (Hussein and Plateau 2003).

The AKRSP was selected as a case study because of its immense importance, success, and worldwide reputation in the microfinance sector, especially in rural development. The World Bank has evaluated the performance of the programme several times over the past two decades and is considered to be highly successful with regard to outreach and efficiency (Nyborg and Ali 2005, World Bank 2002). The AKRSP made a noticeable impact in the area of poverty reduction and demonstrated the success of its model at an international level during the late 1980s and the 1990s (Campos et al 2004). The World Bank's Operations Evaluation Department, after conducting a fourth independent evaluation of the AKRSP's performance covering a period of 18 years of the programme's life, awarded it a "highly satisfactory" rating, the Bank's highest technical rating (World Bank 2002).

For the purpose of this study and the analysis of the empirical data, I have divided the life of the Aga Khan Rural Support Programme into three phases. Figure 6.1 depicts these three phases. Phase I (1982-1995) refers to the time period before the external environmental 'turbulences' affected the AKRSP. Phase II (1996-2001) refers to the timeframe during which the AKRSP adapted or reoriented itself to the new environmental condition. Phase III (2001

\footnotetext{
${ }^{4}$ Agricultural sector growth rate decreased from 6.7 percent to 2.5 percent, while manufacturing sector growth rate slowed down from a whopping 12.6 percent to 8.6 percent during the year (SPDC 2006).

${ }^{5}$ The AKRSP was established in 1982 in the northern region of Pakistan with the primary objective of eradicating regional poverty. It is a subsidiary institution of The Aga Khan Foundation (AKF) which is a privatesector philanthropic network established by the Aga Khan. The AKF seeks to promote social development, primarily in low-income countries of Asia and Africa, through funding programs in health, education and rural development. The Foundation is registered in Switzerland (1967) and has its Head Office in Geneva. Its branch offices are in many countries all over the world. The Foundation selects beneficiaries without any regard to religion, race, or political preferences (World Bank 1995, p.ii).
} 
onwards) relates to the time period after the radical transformation of the AKRSP to The First Microfinance Bank in response to these environmental 'turbulences'.

\section{THE RESEARCH ISSUE.}

This study will explore the AKRSP's adaptation, reorientation, and subsequent transformation to a commercial setup in response to the changed external conditions in the light of Laughlin's (1991) Model of Organizational Change. Organizational adaptation and reorientation in response to the environmental 'disturbances', 'kicks', or 'jolts' (Laughlin 1991), in the microfinance sector, has not been studied and analysed in detail so far and is an interesting area to research, especially to one who has had a long-term association with the banking profession ${ }^{6}$.

\subsection{OBJECTIVES OF THE STUDY.}

In this case study the primary focus is on the actual changes in the AKRSP's 'tangible' and 'intangible' organizational elements - the 'interpretative schemes (objectives, missions, beliefs, norms, values, culture, rules, philosophy), the 'design archetypes' (overall organization structure, decision processes, communication systems), and the 'sub-systems' (tangible organizational elements like staff, departments/divisions, business premises) in response to the changed environmental conditions. Although, the paper will discuss to a limited extent the positive outcomes of the transformation of the Microfinance Division of the Aga Khan Rural Support Programme to an independent commercial microfinance institution in terms of its gradual movement towards operational and financial self-sufficiency, gauging the impact of the microfinance institution on poverty alleviation in the area of its operation is beyond the scope of this study. The focus instead is on how the AKRSP's microfinance division successfully adapted, reoriented, and then subsequently transformed to an independent commercial setup in order to cope with the changed external circumstances, and what the implications were for the development of the relevant theoretical model.

\section{THE THEORETICAL FRAMEWORK FOR THE STUDY.}

The AKRSP's adaptation, reorientation, and transformation in the process of coping with the changed external conditions will be examined from one angle: from the perspective of the actual change in its different organizational elements to best cope with the changed external circumstances and thus ensure its long-term survival.

The empirical data pertaining to the changes in the Aga Khan Rural Support Programme's tangible and intangible organizational elements during its adaptation, reorientation, and subsequent transformation in response to the changed environmental conditions are analysed through the lens of Laughlin's (1991) Model of Organizational Change.

\subsection{LAUGHLIN'S MODEL OF ORGANIZATIONAL CHANGE.}

Figure 1 below diagrammatically represents Laughlin's (1991) Model.

\footnotetext{
${ }^{6}$ The author is a commercial banker by profession and has served in the commercial banking sector in Pakistan from March 1995 to February 2003.
} 
Figure 1: Laughlin's Model (1991) for interpreting organizational change in response to external environmental disturbances.

Source: Adapted from Laughlin (1991).

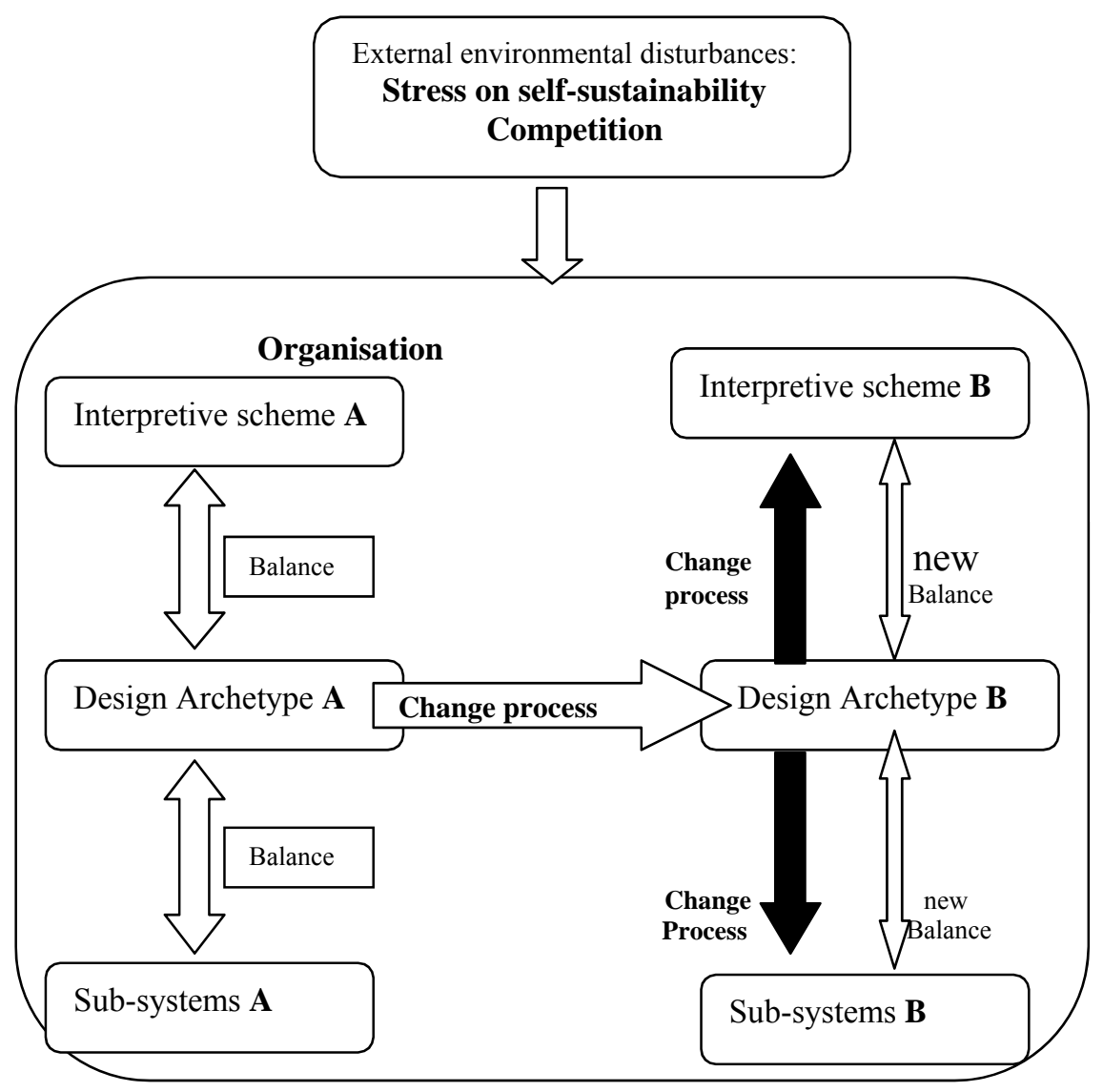

Laughlin (1991) asserts that an organization keeps functioning in a 'balanced' state of its three main organizational elements - 'design archetypes', 'interpretative schemes' and 'subsystems' - unless 'disturbed/kicked/jolted' by an external environmental turbulence(s), stirring its existing 'balanced' state and compelling it to adapt, reorient and/or transform itself in order to cope with the new environmental conditions. The external environmental disturbance(s) initiates a change in the organization's 'design archetype' (the organization structure, decision processes, communication systems), which, in turn, leads to a change in its 'interpretative schemes' (the mission/objectives, beliefs/values/norms/culture, and the organization rules and policies) and 'sub-systems' (tangible organizational elements, like buildings, premises, machines, finances, locations).

The organization, after adapting, reorienting, and/or transforming (depending on the severity of the external disturbance) in response to the changed external conditions, settles or attains a new 'balanced' state of its organizational elements.

\section{THE RESEARCH METHOD.}

Qualitative research, being a flexible approach to a research endeavour, allows several research methods, such as grounded theory, ethnography, and case study to undertake a research (Franfurter and McGoun 1996). This study uses 'case study' as the method of 
research. A case study research is different to other forms of research. It is an inquiry type of study where a researcher's focus is on describing, understanding, predicting, and/or controlling an individual entity in its real life context (Woodside and Wilson 2003). Yin (2003, p. 13) defined a case study research methodology as:

...an empirical enquiry that investigates a contemporary phenomenon within its real-life context and in which multiple sources of evidence are used.

For a case study to be effective, the researcher must not leave any loophole in the process of observation of real life events. The conclusions drawn from a case study takes into account the perceptions and views of all the actors involved in the research process including the researcher (Zonabend 1992). Case study methodology is often resorted to when researchers try to answer 'how' and 'why' questions (Yin 1994). There are different types of case studies. A case study can be categorized as exploratory, descriptive, and/or explanatory. An 'exploratory study' is basically conducted to explore reasons for particular practices observed in a real life setting. A 'descriptive study' is often used to describe contemporary practices, may be to develop a new practice or polish an existing one. An 'explanatory study' is conducted mainly to explain the reasons for observed practices. Any one study can also be categorized as having all, exploratory, descriptive, and explanatory, aspects (Yin 2003). This study can be grouped with 'exploratory' case studies, as it tries to 'explore' the adaptation and reorientation of an organization in response to external 'shocks' or environmental pressures.

\subsection{THE COLLECTION AND ANALYSIS OF THE DATA.}

The empirical data was collected in Pakistan. The field work for this study comprised of two parts and was conducted over a period of three months. The survey of print media and the analysis of archival documents were conducted during the months of July and September, 2006, while interviews with the organizational members at both the Aga Khan Rural Support Programme and The First Microfinance Bank Limited were conducted during the month of August, 2006. During this field work, offices of the AKRSP, and the main offices of The First Microfinance Bank Limited in Islamabad were visited a number of times. The Central Directorate of the State Bank of Pakistan located in Karachi was also visited during the field work. In addition to collecting some printed material pertaining to both the institutions from the Microfinance Wing of the State Bank of Pakistan, one of its inspectors was also interviewed. A total of sixteen ${ }^{7}$ interviews were conducted. As argued by Layder (1993), researchers attempting to utilize a case study approach, must ensure excess to all the relevant information within and outside the organization, and also not to bias research findings. This study enjoyed extensive data access and tried, at its best, to keep the researcher's bias at a minimal level to enhance the validity and reliability of the findings.

As informed by Strauss and Corbin's (1990) study the selection of interviewees was done through a 'purposive sampling' strategy, which involved the targeting of individuals on the grounds of their strategic importance to the AKRSP's change process. Under the 'purpose sampling' strategy, researchers, depending on the nature of research they are undertaking, decide on how many organizational members they want to interview to collect adequate data

\footnotetext{
${ }^{7}$ Sixteen interviews gave the researcher enough data to rely on when complemented by the empirical data gathered from other sources. According to Kuzel (1992) and Fossey et al (2002) there is no minimum or maximum limit on the number of interviews under qualitative research. However, interviews with organizational members should continue until a saturation point is reached. A saturation point in case of qualitative research is one where same facts start emerging time and again, and the researcher does not get any new information from subsequent interviews (Kuzel 1992, Fossey et al 2002).
} 
required for analysis, explanation, and concluding their research endeavour. Under the sampling strategy, researchers have the liberty to decide to exclude some of the organizational members, already interviewed, if they think their attitude to the research issue did not satisfy them, or the information they divulged did not help their research (Mason 2002, Yin 1994). Keeping the objectives of the study in sight, interviewees were selected for the study on the bases of their long-term association with both the Aga Khan Rural Support Programme and The First Microfinance Bank Limited at the top- and middle-management levels ${ }^{8}$. A total of sixteen ${ }^{9}$ interviews were conducted including interviews with the president of The First Microfinance Bank Limited, the Chief Operating Officer at the Pakistan Microfinance Network, Regional Manager at the Rural Support Programme Network, and General Manager at the Aga Khan Development Network. Secondary data was collected from a variety of sources including print media (news papers and magazines), annual reports, minutes of meetings of the board of directors, and the archival documents.

The task of analysis of the empirical data under a case study research methodology is accomplished by finding organized sets of observed patterns in the data (Mayer et al 1995). This procedure was observed in this case study, where different sets of observed patterns were developed about important aspects of the adaptation, reorientation and subsequent transformation of the Microfinance Division of the Aga Khan Rural Support Programme to a commercial setup in response to the changed external conditions using the empirical data. The next step followed was to match these sets of 'observed patterns' with their corresponding sets of 'theoretical patterns' (Mayer et al 1995) that, in this case study, were derived from Laughlin's (1991) Model of Organizational Change.

Yin (1998) identifies three dominant modes of analysis for a case study data: pattern matching, explanation building, and time series analysis. Pattern matching, among these, developed by Trochim (1989), is regarded as the most desirable method of analysing case study data (Yin 1994 and 1998), because it allows researchers to match the observed patterns found in the empirical data with their corresponding theoretical patterns, and provide necessary explanations of the results (Trochim 1989). If the patterns observed in the empirical data coincide with those predicted under the case study's theoretical framework, it will ensure strengthening the 'internal validity' of the study (Yin 1994, p. 106). This case study used 'pattern matching' as a method of analysis of empirical data.

\footnotetext{
${ }^{8}$ After the AKRPS's transformation to the bank, the services of all its microfinance staff were either transferred to The First Microfinance Bank or they joined other institutions in the same field at the AKRSP's request or on their own; therefore, most of the interviewees were from The First Microfinance Bank Limited and other umbrella institutions in the microfinance field.

${ }^{9}$ Keeping in sight the objectives of the study, only those employees were interviewed who have had long-term association with the AKRSP.
} 


\title{
5.2. PATTERN MATCHING MODEL.
}

Figure 2: Patterns Matching Model for a Case Study Data Analysis.

Source: Trochim (1989, p. 356).

\section{Process of Pattern Matching: \\ A. Theoretical Realm \\ (Laughlin Model) \\ B. Theoretical Patterns:}

1. Laughlin (1991) Model: Organizations adapt, reorient, and/or transform in response to unavoidable external environmental disturbances;

\section{Observed Patterns}

1. The actual/observable changes introduced by the AKRSP's management in its structure, communications systems, policies, practices, rules, missions, cultures, and other tangible and intangible elements in response to the external environmental disturbances.

\author{
D. Case Study primary and secondary data. \\ E. Analysing Case Study Data: \\ Patterns Coding \\ Matching the 'observed patterns' with the 'theoretical patterns' \\ F. observations / conclusions.
}

This case study adopted Trochim's (1989) pattern matching model shown in Figure 2 above. The top section of the pattern matching model shows the theoretical realm. Researchers may derive different sets of theoretical realms from the underpinnings of a theoretical framework(s), their own ideas and/or experience, or a combination of both (Trochim 1989). The lower section of the pattern matching model indicates the realm of observations that are derived from the primary and secondary data. Pattern matching is carried out with a view to establish a describable relationship between 'theoretical' patterns, which are suggested by and extracted from established theoretical framework(s), and 'observed' patterns that are developed using the empirical data collected for a case study. The two sets of patterns are then compared and conclusions reached (Trochim 1989).

As the main aim of the study was to explore the changes in the tangible and intangible organizational elements the Microfinance Division of the Aga Khan Rural Support Programme in response to the external environmental disturbances, the empirical data allowed sufficient room to build different sets of 'observed patterns' about the different aspects of the organizational change. These 'observed patterns' were then compared with the 'theoretical patterns' suggested by Laughlin's (1991) Model of Organizational Change and conclusions drawn. In this case study, observed patterns are the changes introduced by the management in the Aga Khan Rural Support Programme's tangible and intangible organizational elements in response to external environmental disturbances.

\section{MATCHING THE PATTERNS.}

In the case of an exploratory case study, if comparison between the observed patterns and the theoretical patterns coincide, it depicts that the results will assist to strengthen the case study's internal validity (Yin 1994). A 'theoretical pattern' represents different scholars' suppositions, expressed in the form a theory and established over time, about what is expected in the data, and an 'observed pattern' is one which is derived from the empirical data of a real life case study (Trochim 1989). The advancement of knowledge occurs when observed patterns, developed through the empirical data in a particular case study, continuously yield the same 
trends as predicted by an established theoretical framework and expressed in the form of theoretical patterns (Yin 1994).

\subsection{EMPIRICAL DATA - 'OBSERVED PATTERNS' AND 'THEORETICAL PATTERNS'.}

In 1996 the Aga Khan Rural Support Programme (AKRSP) committed itself to building a financially sustainable microfinance programme; to meet this goal, the AKRSP underwent a complete reorientation phase from 1996 to 2001 and, in 2001, its microfinance division transformed into an independent commercial institution in 2001. The outcomes for the AKRSP as shown in the table were all derived from the empirical data. At the reorientation stage, the external environment is relatively less aggressive and the extent of change it wants an organization to go through is manageable (Hill and Collins 2000). The same situation can be observed from the reorientation phase of the Aga Khan Rural Support Programme. The microfinance operations at the AKRSP were not geared towards financial self-sustainability until the end of 1995 (AKRSP 2000). The AKRSP management, at this juncture, decided to adapt and reorient its microfinance operations to the changed environmental conditions and, thus, tailor them to financial self-sustainability. The following sections will throw light on the changes to the AKRSP's 'interpretative schemes', 'sub-systems', and 'design archetypes' in response to the changed environmental conditions. While a huge amount of empirical data was collected for the study, a limited amount is used in this paper keeping in view its desirable length. The empirical data collected for the study covered three phases of the AKRSP's life as shown in Table 1 below.

Table 1: Organizational transformation in the AKRSP - a preliminary sketch of all the three phases of organizational change.

\begin{tabular}{|l|l|l|l|}
\hline Description & Phase I & Phase II & Phase III \\
\hline Timeframe & $1982-1995$ & $1996-2001$ & 2001 onwards \\
\hline $\begin{array}{l}\text { Organizationa } \\
\text { 1 Form }\end{array}$ & $\begin{array}{l}\text { Non-governmental } \\
\text { Organization (NGO) }\end{array}$ & Adapting and reorienting & $\begin{array}{l}\text { Regulated commercial } \\
\text { bank }\end{array}$ \\
\hline $\begin{array}{l}\text { Laughlin's } \\
\text { Model }\end{array}$ & Morphostatic rebuttal & Morphostatic reorientation & Morphogenetic Evolution \\
\hline
\end{tabular}




\begin{tabular}{|c|c|c|c|}
\hline $\begin{array}{l}\text { Interpretive } \\
\text { Schemes }\end{array}$ & $\begin{array}{l}\text { Poverty eradication, } \\
\text { Not-for-profit } \\
\text { operation, local } \\
\text { infrastructure and } \\
\text { agricultural } \\
\text { development, informal } \\
\text { organizational culture, } \\
\text { dependence on donors }\end{array}$ & $\begin{array}{l}\text { Poverty eradication with } \\
\text { stress on cost control, } \\
\text { struggle for self- } \\
\text { sustainability and } \\
\text { profitability, adopting } \\
\text { formal organizational } \\
\text { culture, struggling to } \\
\text { achieve independence }\end{array}$ & $\begin{array}{l}\text { For-profit operation, } \\
\text { Poverty eradication using } \\
\text { commercial approach, } \\
\text { business culture, } \\
\text { customer-orientation, } \\
\text { formally setting targets } \\
\text { for profitability and self- } \\
\text { sustainability, using } \\
\text { commercial approach in } \\
\text { all operations, strictly } \\
\text { formal and regulated } \\
\text { culture, complete } \\
\text { independence. }\end{array}$ \\
\hline $\begin{array}{l}\text { Design } \\
\text { Archetype } \\
\text { including } \\
\text { Accounting } \\
\text { system }\end{array}$ & $\begin{array}{l}\text { Poorly implemented } \\
\text { organizational } \\
\text { hierarchy, negligible } \\
\text { accountability, low } \\
\text { internal control, poorly } \\
\text { defined decision- } \\
\text { making powers, } \\
\text { informal and verbal } \\
\text { internal } \\
\text { communication, } \\
\text { shortcomings in } \\
\text { accounting systems and } \\
\text { MIS. }\end{array}$ & $\begin{array}{l}\text { Restructuring the } \\
\text { organizational hierarchy, } \\
\text { opening and merging of } \\
\text { departments, defining and } \\
\text { implementing } \\
\text { accountability, improving } \\
\text { internal control, improving } \\
\text { decision-making processes } \\
\text { and internal } \\
\text { communication, adopting } \\
\text { formal accounting } \\
\text { principles, orienting } \\
\text { towards MIS }\end{array}$ & $\begin{array}{l}\text { Formally implementing } \\
\text { well-defined } \\
\text { organizational hierarchy, } \\
\text { professionalism, well- } \\
\text { defined internal control, } \\
\text { formal accountability } \\
\text { system, assigning formal } \\
\text { decision-making powers, } \\
\text { full-fledge use of MIS } \\
\text { and Accounting } \\
\text { principles }\end{array}$ \\
\hline Sub-system & $\begin{array}{l}\text { Untrained and inexpert } \\
\text { staff, Un-standardized } \\
\text { branch buildings, } \\
\text { poorly designed } \\
\text { interior and exterior of } \\
\text { office buildings, non- } \\
\text { commercial location of } \\
\text { branches. }\end{array}$ & $\begin{array}{l}\text { Staff training programs, } \\
\text { internal transfers of staff, } \\
\text { achieving standardization } \\
\text { in branches, improving } \\
\text { interior and exterior of } \\
\text { branches, evaluating the } \\
\text { branches location, } \\
\text { considering branches } \\
\text { attractiveness and clients' } \\
\text { comfort }\end{array}$ & $\begin{array}{l}\text { Hiring of professional } \\
\text { staff, complete } \\
\text { standardization of } \\
\text { branches, business } \\
\text { feasibility report for } \\
\text { branches openings, } \\
\text { opening of branches in } \\
\text { commercial locations, } \\
\text { closing of extremely } \\
\text { undesirable branches }\end{array}$ \\
\hline
\end{tabular}

\subsection{PHASE II - THE AKRSP'S REORIENTATION.}

Table 2 below gives a clear picture of how the AKRSP's reorientation process, initiated in the beginning of 1996, was demonstrated by a number of key indicators. The Programme's performance during the period from 1998 to 2001 has been remarkable and its efficiency has been satisfactory in terms of the costs of achieving these results (World Bank 2002). 
Table 2: The AKRSP's Microfinance Operations 1998-2000.

Source: Adapted from AKRSP (2000).

\begin{tabular}{|c|c|c|c|}
\hline AKRSP's Microfinance Operations & 1998 & 1999 & 2000 \\
\hline 1. Average Performing Assets ${ }^{10}\left(\mathrm{PRS}^{11}\right.$. Millions) & 326 & 476 & 565 \\
\hline 2. Outstanding Loan Portfolio ${ }^{12}$ (PRS. Millions) & 253 & 201 & 142 \\
\hline 3. Outstanding Portfolio per Borrower (PRS.) & 7,423 & 7,523 & 6,522 \\
\hline 4. Credit Portfolio at Risk ${ }^{13}$ & $4.2 \%$ & $7.2 \%$ & $5.6 \%$ \\
\hline 5. Operating Cost to Avg. Performing Assets Ratio ${ }^{14}$ & $5.7 \%$ & $4.0 \%$ & $3.6 \%$ \\
\hline 6. Operating Cost to Avg. Loan Portfolio Ratio ${ }^{15}$ & $7.1 \%$ & $8.5 \%$ & $11.9 \%$ \\
\hline 7. Operational Self Sufficiency & $197 \%$ & $219 \%$ & $353 \%$ \\
\hline 8. Financial Self Sufficiency & $81 \%$ & $107 \%$ & $186 \%$ \\
\hline 9. Adjusted Return on Performing Assets ${ }^{16}$ & $-3.8 \%$ & $0.8 \%$ & $7.3 \%$ \\
\hline
\end{tabular}

The discussion here will focus on the AKRSP's adaptation and the reorientation in response to the two environmental 'disturbances' - first, the donors' changed approach and thinking about the sustainability of the microfinance institutions, and, second, the resulting competition among the MFIs. According to participant no. 15, Senior Operations Associate at the First Microfinance Bank Limited, senior management at the AKRSP, soon after the 'disturbances' affected the MFI during the mid-1990s, chalked out a major plan to first gradually adapt and reorient the MFI and then completely transform it to a new independent commercial setup. The AKRSP Board of Directors appointed the Strategy Development Committee in 1994 to propose a future direction for the Programme (World Bank 1995). The change was evident as noted in the AKRSP's annual review of 1995. It read:

the institutional map of the microfinance sector is changing. In response, the AKRSP is also revamping many of its support services. The year 1995 began with a bottom-up review of various programme elements in response to the emerging programmatic needs in the microfinance field. The Village/Women's Organizations (V/WOs) members, as well as field staff, were consulted during the year to streamline delivery and feedback systems, and to improve existing, or design new programmes in the light of changing needs, new trends, opportunities, and challenges in the microfinance sector (AKRSP 1995).

During the change process, during 1997, the capacity of the Policy and Research (P\&R) section was strengthened in order to develop and support important initiatives for the

\footnotetext{
${ }^{10}$ It depicts the AKRSP's successful drive towards self-sustainability.

${ }^{11}$ Pakistani Rupees

${ }^{12}$ In accordance with the plan chalked out after the changes initiated in the AKRSP to first reorient and then transform it to a completely independent commercial setup, the outstanding loans portfolio was reduced gradually by recovering the existing loans and limiting sanctioning new loans.

${ }^{13}$ This increasing trend might have been because of the borrowers' learning about the AKRSP's plans about the proposed bank (AKRSP Annual Report 1999).

${ }^{14}$ This trend depicts the effective implementation of the cost control policies incorporated after the change.

${ }^{15}$ The increasing trend in the ratio is due to the contracting outstanding loan portfolio.

${ }^{16}$ This trend depicts the optimal use of the performing assets and investment of idle funds after maintaining sufficient liquidity.
} 
programme. Key functions of the $P \& R$ included the refinement and strengthening of programme planning and reporting systems, participating in and leading strategic discussions relating to issues of gender, equity, and sustainability, and the dissemination of information relating to the programme both within the AKRSP and to external organizations (AKRSP 1997).

\section{CHANGES TO THE AKRSP'S 'INTERPRETATIVE SCHEMES'.}

Looking at the empirical data, observed patterns ${ }^{17}$ were developed and then looked at with the lenses of the 'theoretical pattern' suggested by Laughlin's (1991) Model of Organizational Change.

\section{1. 'THEORETICAL PATTERN- SET A $\tau$ '.}

According to Laughlin's (1991) Model of organizational change, an organization keeps functioning in a 'balanced' state without a noticeable change unless an external environmental 'turbulence', 'disturbance', 'kick', or a 'jolt' disturbs its existing state of 'balance' and compels it to adapt and reorient to its new external environment. Among other changes, the organization has to tailor its 'interpretative schemes' - the organization's missions/objectives, policies/rules, internal procedures, values/cultures/philosophy, etc. - to become harmonized with its external environment.

\section{2. 'OBSERVED PATTERNS- SET Ao'.}

Using the primary and secondary data collected for this study, the following provides a discussion of the changes in the Aga Khan Rural Support Programme's 'interpretative schemes' to cope with its changed circumstances.

\subsubsection{OBJECTIVES/MISSIONS.}

During the process of adaptation and reorientation the Aga Khan Rural Support Programme went through numerous changes to its objectives/missions, values/norms/culture, and rules, procedures and policies (the 'interpretative schemes' in terms of Laughlin's (1991) Model). Participant no. 2, the CEO of the Pakistan Microfinance Network, observed that during the reorientation process, for the first time ever, the AKRSP began to measure what was happening within the organization in terms of productivity, efficiency, portfolio quality, and financial sustainability. Participant no. 4, the General Manager of the Aga Khan Development Network, remarked in this context that many policies and rules, from maintaining the office kitchen to hiring staff, were all changed. Internal procedures from approval for office cars maintenance expenses to the purchase of official vehicles for executives were all changed.

"...policies about the size of loans and loans approval procedures were also changed", he further added.

Soon after the change, concrete efforts were made to improve Fund Management. Management started to prudently invest idle funds with banks to earn a profit. The purpose was to make sure that sufficient funds were available for credit operations while idle funds were at a minimal level (AKRSP 2000). As per the Government of Pakistan, Finance Division Order dated 27th February, 1982, the primary objectives of the AKRSP were 'rural uplift',

\footnotetext{
${ }^{17}$ While a huge amount of empirical data could support the development of different sets of 'observed patterns', only limited amount of it have been used to restrict the size of the paper to a desirable length.
} 
'development of land resources', and any other 'welfare activities'. The 'Order' clearly requires the company to apply its profits, whencesoever derived, and revenues towards these objectives, and prohibits the company from paying any dividend or profit to its members (Government of Pakistan Order 1982, AKRSP's Memorandum of Association, p. 7). This 'Order' clearly depicts that 'earning profit' was not among the primary objectives of the AKRSP. The Memorandum of Association ${ }^{18}$ of the AKRSP lists the following among its main objectives:

-To accept grants from any governments or agencies or authorities, public bodies, corporations, companies, movable and immovable property, donations, gifts, subscriptions, and other assistance with a view to promoting the objects of the company, and,

-To take such steps by personal or written appeals or otherwise as may from time to time be deemed expedient of the purpose of procuring contributions to the funds of the company in the shape of donations or annual subscriptions.

These objectives clearly depict that the AKRSP's inception and existence was meant to be donor-dependent. Participant no. 4, General Manager Aga Khan Development Network, said in this regard that the core objective of the AKRSP was to reach the poor people of its area of operations with micro loans to help them get out of the poverty. After the change was initiated, one more basic objective was added - to achieve the first objective but now in a sustainable manner. So the responsibility of ensuring sustainability came over the MFIs' own shoulders. Similar views were shared about the change in objectives by Participant no. 5, the General Manager of the Pakistan Microfinance Network, and no. 8, the Head of the Marketing and Product Innovation department at the First Microfinance Bank.

\subsubsection{POLICIES AND RULES.}

After the change process was initiated at the AKRSP, sound and prudent policies were implemented in order to ensure the satisfactory accomplishment of the set objectives. Partcipant no. 11, the Chief Operating Officer of the Pakistan Microfinance Network, said that there were no written policies and procedures at the AKRSP before the change and no policy document was developed. He went on to say that "...every operational aspect was informally functioning without any policy document until I developed and implemented one after the change initiated in the AKRSP during 1995/1996". The objective of financial selfsustainability was added to the existing objectives, and the requirement of cost efficiency was added to the AKRSP's 'principles of operations' (AKRSP's Internal Policies \& Procedures Manual 1996).

To achieve the much-needed profitability, an increase in business volume, and cost control are the two obvious means to resort to. Discussing a policy change about cost control, participant no. 2, the Chief Executive Officer of the Pakistan Microfinance Network, remarked that stiff policies were implemented to ensure the profitability and productivity of the microfinance operations. In addition, staff productivity was more regularly observed and evaluated after the change. After the change, the programme carefully selected new microfinance officers and efforts were made to lift their, and the existing microfinance officers', credit appraisal and loan portfolio management skills (AKRSP 2000).

\footnotetext{
${ }^{18}$ It is a legal document submitted to the concerned government ministry in Pakistan before the incorporation of a company; it depicts and describes the objectives of the company's existence, operations, and the permitted range of the company's activities and powers.
} 
About the new policy of cost control, participant no. 4, The General Manager, Aga Khan Development Network (AKDN) said, “...we as staff experienced high stress for cost control after the change. Before the change, we had no such things like budgeting for costs, profits, and targets for loans, number of clients reached, etc."

The same trend in cost control prevailed till the end of the AKRSP's reorientation phase at the beginning of 2002 as depicted at the AKRSP's Board of Directors meeting dated 27th and 28th January, 2001. In the meeting it was noted that the 2001 budget projected a deficit of Pak rupees 2.4 million (excluding the investment income). The constant struggle of the AKRSP to sustain the outreach of the Programme in the face of a falling volume of loans, and therefore the service charge income, was cited at the Board meeting as the reason for the deficit.

Participant no. 9, the Head of the Operations Department, First Microfinance Bank Limited, said that policies from staff recruitment to the utilization of their services were all changed. Adding further to his comments, participant no. 9 said, “....after the change initiated in the AKRSP, most of the new staff hired were from commercial institutions with a purely commercial background; the purpose was to operate the MFI by commercial-minded staff'. Participant no. $10^{19}$, the Regional Manager of the Rural Support Programmes Network, expressed more or less same views in this regard. Participant no. 11, the Chief Operating Officer of the Pakistan Microfinance Network, remarked that since staff members were the face of an institution, after the change they introduced a lot of prerequisites for hiring new staff in the staff recruitment policies. He went on to say, "...our new policy in this respect was that if we hire good staff and pay them well, they will work hard for your good name and reputation".

\subsubsection{INTERNAL PROCEDURES.}

At the Aga Khan Rural Support Programme (AKRSP), internal procedures were not geared towards professionalism and informality prevailed in almost all its operations. The AKRSP was functioning but there were no written manuals of policies and procedures and no accounting standards followed or observed. That time, before the change, there used to be only verbal office orders on different operational aspects. So in the field or in operations, different people were applying different methodologies for loans disbursement and recoveries, and other operations (Participant no. 11). “...I developed manuals for different operational aspects are the AKRSP. This happened during 90s and we had these different manuals ready almost in 1997", Participant no. 11, the Chief Operating Officer of the Pakistan Microfinance Network, further remarked in this connection. In the AKRSP's manual for policies and procedures, developed in 1996 by participant no. 11, numerous new internal rules and policies were implemented for the efficient and cost effective operation of the microfinance operations at the AKRSP. For instance, a revised system of compensation for the Village Accountants (VAs) was introduced and implemented through the policies and procedures manual at the AKRSP in $1996^{20}$. 'Moving from subsidized group lending towards commercial lending' and 'flexible and decentralized management systems' were named elements of self-sustainability

\footnotetext{
${ }^{19}$ Ex-Head of Finance Portfolio at the AKRSP (1986-2006).

${ }^{20}$ The VAs' job was to help the Village Organizations (VOs) and Women's Organizations (WOs) in accounting matters and impart training to the V/WO managers. Before the change, the VAs were allowed a fixed remuneration. In 1996 the compensation system was changed and the AKRSP started compensating them on a 'work done' basis to improve the efficient utilization of their services (AKRSP's Internal Policies \& Procedures Manual 1996).
} 
and were followed in letter and spirit after the external disturbances impacted on the Aga Khan Rural Support Programme (AKRSP's Internal Policies \& Procedures Manual 1996).

Before the change there was no system of internal audit; in 2000, the main office established an Internal Loan Portfolio Audit System and appointed one of the Microfinance Officers to the post of 'Internal Auditor' (AKRSP 2000). Talking about procedural change participant no. 4, the General Manager of the Aga Khan Development Network said that through his experience he could say that poor people were more honest and credible, and would honour their commitment, if the assistance was in line with their specific requirements and ability to repay. He further added to his comments that, “...that is why, in our internal loan processing procedures, we incorporated another step and that was the internal assessment of the actual loan requirement of the borrower; we listed it in the responsibilities of the credit and monitoring department."

In the process of rearranging the internal procedures, the microfinance programme's costs, budget, and income were separated from the rest of the Aga Khan Rural Support Programme's activities. Excess funds held in various AKRSP accounts were allocated to the microfinance programme's credit pool and any funds from this pool in access of the loan portfolio were invested with different banks to earn a profit. During this reorientation phase, a manual of credit policies and procedures was written and implemented to improve the management of credit operations (AKRSP 2000).

About the change in loan processing procedures, participant no. 3, the Head of the Finance Department at the First Microfinance Bank, remarked that before the change, they used to take a lot of time in loan processing; after the change, although credit volume curtailed significantly, they made the procedure simpler eliminating a lot of paper work, and set a standard processing time of two days for a loan application. In addition, the AKRSP also started giving training and expert advice to its borrowers, which practice was not prevalent before the change initiated in the AKRSP (participant no. 3).

In the face of competition, product innovation and adaptation to customers' needs is one of the important keys to success. The AKRSP Board of Directors noted similar concerns in its meeting dated 27th and 28th January, 2001 wherein it was resolved that in order to help make the programme more responsive to client needs and more sustainable, new products would be launched from time to time. In the meeting the members pointed to a recently innovated 'business committee' product as an example; they also pointed to another "leasing product" that was proposed to be developed in that year. Poorly performing products were gradually abandoned (AKRSP 2000). To cope with competition among the MFIs, participant no. 5, the General Manager of the Pakistan Microfinance Network, said that they went beyond credit and gradually, with the passage of time, started a full range of financial services, like mobilizing public savings, micro-insurance, remittances, and 'training and expert advice' services in our product-line. Talking about the procedural change in entertaining a loan request from a poor borrower, participant no. 13, the President of The First Microfinance Bank, said that instead of sanctioning whatever amount requested by a poor borrower, they started doing their internal evaluation and assessment of the requirements of the borrower and accordingly an increased or decreased amount was actually sanctioned to the poor borrower. "...we have even given bigger loans than the requested amount of the borrower because our internal analysis of his financial needs showed that for the successful implementation of his particular project he needed more than he had requested". 


\subsubsection{ORGANIZATIONAL PHILOSOPHY AND OVERALLCULTURE.}

In the literature there are various proposed classifications of organizational culture (see, for instance, Chang and Wiebe 1996, and Gould 1996). Gould (1996) has proposed that each stage of an organizational transition, before and after the change, requires a matching culture that best describes a particular phase the organization is going through. Gould (1996) further argues that an organizational culture protects and sustains the organizational core competencies, beliefs, and codes of conduct, and it also determines the behaviours that pervade the organization.

When an organization adapts or reorients to external environmental conditions, the management tries to adjust or tailor the overall organizational culture and promulgates a specific organizational philosophy. At the Aga Khan Rural Support Programme the overall organizational culture was surrounded by the 'social organization' principle of rural development (AKRSP 1997). The new environmental conditions had a profound effect on the overall organizational culture and operational philosophy. Participant no. 4, the General Manager of the Aga Khan Development Network, said in this context that after the change, overall organizational culture was about efficiency and cost control. The informality in the overall organizational culture in the AKRSP changed to a more formal and professional internal environment. Participant no. 12, an officer in the Marketing and Product Innovation department at the First Microfinance Bank, said that efforts were made during the first two to three years of change on institutional capacity building within the AKRSP. Participant no. 13, the President of The First Microfinance Bank, said that the organizational philosophy at the AKRSP was totally opposite to that of a perpetual entity. After the change was initiated, it tailored its overall organizational philosophy to make it compatible with that of a commercial and perpetual organization. The participant further added that they built institutional capacity, and developed and implemented professional standards within the AKRSP.

\section{CHANGES TO THE AKRSP’S ‘SUB-SYSTEMS’.}

Using the empirical data, here again 'observed patterns' will be developed and then looked at with the lenses of the 'theoretical pattern' suggested by Laughlin's (1991) Model of Organizational Change.

\section{1. 'THEORETICAL PATTERN- SET B $\tau$ '.}

Laughlin (1991) argues that after external environmental conditions affect an organization, it is compelled to adapt and reorient to its new environmental conditions. Among other changes, the organization has to tailor its 'Sub-systems' - the tangible organizational elements like buildings, premises, staff, locations, assets - to cope with the new circumstances.

\section{2. 'OBSERVED PATTERNS- SET Bo'.}

Based on the primary and secondary data, discussion is will be focused on the changes in the Aga Khan Rural Support Programme's 'sub-systems' that it developed to cope with its changed circumstances. These changes were very prominent, as endorsed by most of the participants in the interviews. Participant no. 5, the General Manager of the Pakistan Microfinance Network, said in this context that the changes in the tangible organizational elements were primarily in response to the combined effects of the changed donors' approach and the resulting competition. Plans for the transfer of all of the AKRSP's microfinance related tangible assets to the proposed commercial microfinance setup were made during the reorientation phase, which were subsequently endorsed by the AKRSP's Board of Directors 
in their meeting in May 2001. It was resolved that physical assets (vehicles, equipments, etc.) belonging to the AKRSP's microfinance section would be transferred to the proposed commercial bank. However, it was left undecided in the meeting as to whether the bank would acquire these assets at a market value or book value. The empirical data showed eminent changes were introduced in the AKRSP's tangible organizational elements including staff, building/premises, business locations, etc.

\section{CHANGES IN THE AKRSP’S ‘DESIGN ARCHETYPE’.}

Here again 'observed patterns' will be developed based on the empirical data and looked at with the lenses of the 'theoretical pattern' suggested by Laughlin's (1991) Model of Organizational Change.

\section{1. 'THEORETICAL PATTERN- SET C $\tau$ '.}

According to Laughlin's (1991) Model when an organization's existing 'balanced' state of operation is 'disturbed' by an external environmental 'turbulence', 'disturbance', 'kick', or a 'jolt', it causes a change in the organization's existing 'balanced' state; the organization, among other changes, has to adjust its 'design archetype' - the overall organizational structure, internal communication systems, use of accounting, and decision processes - to cope with the new external conditions.

\section{2. 'OBSERVED PATTERNS- SET Co'.}

The primary and secondary data that were collected for this study suggests that the 'design archetype' at the Aga Khan Rural Support Programme went through numerous prominent changes during its adaptation and reorientation to the changed environmental conditions in the late 90 s. These changes are discussed here thereby developing a set of 'observed patterns' set $\mathrm{C}$.

\subsubsection{CHANGES IN 'OVERALL ORGANIZATIONAL STRUCTURE’.}

Before the change process was initiated, microfinance operations at the AKRSP were managed by one department. The structural reorientation was carried out through the opening of different departments in the Credit and Savings division (C\&S) of the AKRSP. The C\&S section made considerable efforts throughout 1997 to bring about structural and strategic shifts to its operations with the aim to strengthen its capacities to function as an independent unit within the AKRSP (AKRSP 1997). In the process of reorienting the overall organizational structure at the AKRSP to cope with the new environmental conditions, internal departmentalisation and the organizational hierarchy were mainly 'disturbed' and moved towards a new 'balanced state'.

With regards to structural changes, participant no. 4, the General Manager of the Aga Khan Development Network, remarked that compared to the other changes that the AKRSP went through in the process of its reorientation, the change in the organizational structure of the MFI was the most dominant and prominent one which ultimately led it to the adoption of a completely new independent setup. Participant no. 11, the Chief Operating Officer of the Pakistan Microfinance Network, said in this connection that before the change, earlier at AKRSP they used to have only one main microfinance department with all staff working in it almost collectively; but after the change, they gradually started to formalize their organizational structure. 


\subsubsection{CHANGES IN 'INTERNAL COMMUNICATION SYSTEMS’.}

According to participant no. 3, the Head Finance Department, and no. 8, the Head of the Marketing and Product Innovation Department, internal communication, both upward and downward, was very poor at the Aga Khan Rural Support Programme before the change. Participant no. 4, the General Manager of the Aga Khan Development Network, also expressed similar views about the issue. Participant no. 15, the Senior Operations Associate of The First Microfinance Bank, said in this context that before the change at the AKRSP there was only one formally nominated region covering the whole microfinance operations; after the change, it formally divided the whole area of its operations into two regions - Gilgit and Baltistan, causing an increase in the internal flow of communication. The Head of the Credit and Monitoring department and the Program Manager at The First Microfinance Bank, participants no. 6 and 14 respectively, said in this context that during the MFI's reorientation process internal communication had increased tremendously both in quantity and quality. All this frequency of internal communication had increased gradually with the passage of time, initiating during the late $90 \mathrm{~s}$. After the change, new statements and reports were incorporated into the internal communication system which included information on efficiency, loan portfolio quality, and sustainability (AKRSP 2000). The Head of the Marketing and Product Innovation department, participant no. 8, remarked that the internal communication was not effective at all in the pre-change setup of the AKRSP, and later on, after the change, staff witnessed more and more emphasis on this aspect of the organization. "Internal circulars were more frequently issued to different departments asking for different statements and reports about different aspects of the AKRSP's operations. Later on, these one-off statements and reports were permanently incorporated into the internal communication system", participant no. 8 further added to his comments.

\subsubsection{CHANGES IN 'ACCOUNTING USE’.}

Accounting has been examined over the past in organizational contexts. "Accounting is not a static phenomenon... accounting has been implicated in the creation of very different patterns of organizational segmentation...different managerial functions have come to be emphasized by the changing accounting representation of them" (Hopwood 1987, p. 207). Accounting change is seen as a 'reflective' rather than a 'constructive' organizational endeavour. Different accounting practices are seen as reflecting different organizational circumstances. Accounting changes in order to get better and there can be a number of significant pressures on accounting to change - 'organizational reforms and improvements' is one of them (Hopwood 1987, pp. 209-212).

Looking at the Aga Khan Rural Support Programme's (AKRSP) pre-change scenario, it becomes evident that it was not making use of accounting concepts and principles; the concept of a Management Information System (MIS) was totally ignored and the role of Information Technology (IT) was literally negligible. At the AKRSP's Village Organizations (VOs) and Women's Organizations (WOs) no reserve funds were maintained to meet unforeseen losses and contingencies; even at some VOs/WOs, no accounts or records were maintained at all (Hussein and Plateau 2003).

Financial reporting and internal control are critical for managing a microfinance program but the use of these concepts started at the AKRSP in the late 1990s when it was made compulsory to make a yearly detailed budget projecting costs, income, loan disbursements, and loan recoveries for the year. The management then realized that budgeting is crucial for improving internal control, setting operational targets, maintaining sufficient liquidity, and 
improving fund management. Moreover, the microfinance staff was made to produce a monthly Credit Operations Report (COR) that contained figures on efficiency, credit portfolio quality, and financial sustainability (AKRSP 2000). Participant no. 9, the Head of the Operations Department, The First Microfinance Bank, said in this connection that after the change, gradually a Management Information System was developed and numerous statements and periodical reports, about almost every aspect of the AKRSP's operations, were incorporated after the structural reorientation was completed. These reports and statements were prepared and sent by lower staff to the senior management for day-to-day decision making purposes. Before the change, the AKRSP used to have a manual system to maintain accounts and track the loan portfolio; however, since the beginning 1997 it started to develop and test a computerized Management Information System which would be utilized for management and financial reporting in future. All this clearly depicts the lack of use of accounting concepts and principles at the AKRSP before the change.

\subsubsection{CHANGES IN 'DECISION PROCESSES'.}

During the late 1990s, while the AKRSP was adapting to its changed external conditions, an attempt was made to decentralize the internal decision processes, which resulted in more autonomous and strengthened regional programme offices (AKRSP 1997). The purpose of decentralizing the programme was to provide financial services at the 'doorstep' (AKRSP 2000). The first such change in the decision process occurred in 1997 during the AKRSP's reorientation phase when the credit management responsibility was moved from the AKRSP main office to the Finance Department in each of the three Regional Offices, although not further to the Field Management Units (AKRSP 2000). After this initial decentralization of the internal decision processes, another attempt was made a year later in 1998 to further decentralize lending operations, and microfinance officers in the field were given authority to sanction loans. The purpose of this decentralization was to increase the client base and, keeping in view the overall high loan recovery rate, to increase the profitability of the institution (AKRSP 2000).

However, as demonstrated in Figure 3 below, the AKRSP had to tighten back the lending policy and again centralize the decision making during 1999.

As the graph illustrates, during 1997 and 1998 there was a push to disburse an increasing number of loans, particularly in the Baltistan region. Most of these loans were larger in size and not adequately appraised, which resulted in high levels of loan delinquency by 1999. As a result, the AKRSP's management decided to centralize the lending powers and tighten the lending policy (AKRSP 2000), which, in turn, resulted in reduced credit volumes in 1999 and 2000 , as illustrated in the graph. 
Figure 3: AKRSP's Own and VOs'/WOs' Internal Lending

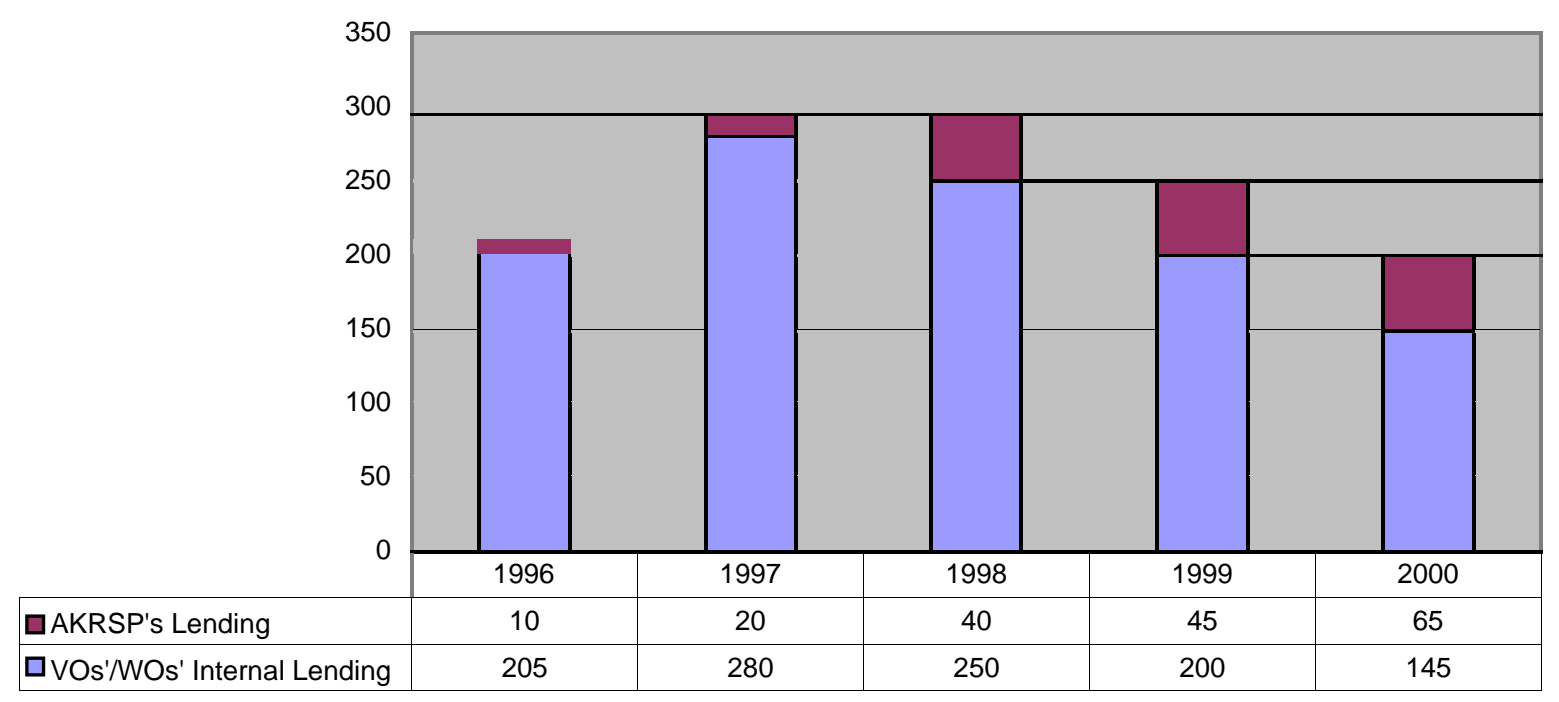

Source: AKSRP (2000).

\section{PHASE III — THE AKRSP'S TRANSFORMATION.}

By the end of 2000, the Aga Khan Rural Support Programme's top management had determined that in view of the prevailing circumstances its microfinance programme would work best if it was managed separately from the AKRSP's other activities (AKRSP, 2000). It is worth-mentioning that the transformation of the Microfinance Division of the Aga Khan Rural Support Programme to The First Microfinance Bank Limited (FMFBL) was internally driven and chosen by the AKRSP's management. This was also pointed to by the Regional Manager of the Rural Support Programs Network, participant no. 10, who said that the idea of transforming the AKRSP into an independent commercial bank was internally driven and was based on the management's realization that in order to achieve the objective of long term selfsustainability the AKRSP must re-establish itself on a purely commercial footing. The President of The First Microfinance Bank, participant no. 13, expressed a similar opinion in this connection. This meant that the AKRSP's new set of 'interpretative schemes' (objectives, polices, philosophy, culture), developed after its reorientation in response to the changed environmental conditions, necessitated another change - the transformation to an independent commercial setup.

The AKRSP's Board of Directors at its meeting in September, 2001 approved the outline of the proposed bank's organizational hierarchy and initial operational targets. After a smooth and successful reorientation, the microfinance programme at the AKRSP was transformed to a completely independent commercial setup and became The First Microfinance Bank Limited in March 2002. The transformation of the AKRSP from a social service setup to a commercial one was not simply a change in its procedures and operations; rather the change was drastic in nature affecting all aspects of the Microfinance Division of the AKRSP. As a result it altogether divested itself of all microcredit operations (Hussein and Hussain 2003). The empirical data collected for the study revealed a similar outcome in the case of the transformation of the Microfinance Division of the Aga Khan Rural Support Programme into 
the First Microfinance Bank Limited, because the AKRSP's highly affected 'interpretative schemes' necessitated full-fledged and mutually reinforcing changes in its 'design archetypes' and 'sub-systems'.

The groundwork for the creation of a separate independent microfinance institution was completed by 2000 (AKRSP 2001). The establishment of the bank was formally discussed at the AKRSP's Board of Directors meeting dated May 26, 2001 when one of the members, who is now the Chief Operating Officer of the Pakistan Microfinance Network, participant no. 11, made a detailed presentation about the plans for the microfinance bank. At the beginning of 1996 the AKRSP began the process of streamlining the microfinance program separately within its existing structure, which was finalized by 2000 (FMFBL Annual Report 2003). The Aga Khan Rural Support Programme's Board of Directors at its meeting on the 23rd of September, 2001 resolved that the AKRSP's entire microfinance programme would be absorbed in the microfinance bank. They resolved that the bank, over the first five years of its operations, would establish 30 branches representing Pakistan's all four provinces. The AKRSP and the Aga Khan Fund for Economic Development ${ }^{21}$ (AKFED) agreed in the meeting to include all these issues in the Memorandum of Understanding (MOU). Also, in the same meeting it was mentioned before the Board members that the crucial discussion of transition issues had begun between the AKRSP and the microfinance bank's tentative top management team ${ }^{22}$.

Finally, the FMFBL was established in November 2001 as a public limited company ${ }^{23}$ under the Company's Ordinance (1984). It was licensed as a microfinance institution in January 2002 under the provisions of the Microfinance Ordinance $2001^{24}$ (AKRSP's BOD ${ }^{25}$ meeting dated January 19, 2002). The AKRSP's Board of Directors resolved at their meeting dated October 26 and 27, 2001 that the entire responsibility to manage the microfinance operations, both the AKRSP and The First Microfinance Bank components, should rest with the bank from day one. That is, The First Microfinance Bank would manage the AKRSP's part of the programme on behalf of the AKRSP, including making and collecting loans until such time as operations are fully taken over by the Microfinance bank. It was resolved at the meeting that the AKRSP's staff should be offered positions by the First Microfinance Bank on terms and conditions to be decided by the bank. The services of the staff who did not accept these offers would be terminated by the AKRSP. The Board of Directors requested the bank's nominated members of the top management team to arrange to prepare and communicate its offers to the AKRSP's staff in order to allow the AKRSP to serve notice to staff members who did not accept the bank's offer.

\footnotetext{
${ }^{21}$ One of the major shareholders of the AKRSP (20\%), and an economic arm of the Aga Khan Foundation (AKF) which is the parent body of all the Aga Khan's projects throughout the world.

${ }^{22}$ Appointments of the bank's President, Chief Executive Officer, and other key position-holders in the management of the proposed bank in addition to the members of its Board of Directors had already been finalised by this time (AKRSP's Board meeting dated September 23, 2001).

${ }^{23}$ Non-listed on the stock exchange.

${ }^{24}$ The Microfinance Institutions Ordinance was promulgated on $16^{\text {th }}$ October, 2001. The Ordinance covers all the microfinance institutions (MFIs) in Pakistan. It was specifically issued to cover the AKRSP's transformation to The First Microfinance Bank.

${ }^{25}$ Stands for 'Board of Directors'.
} 


\section{CONTRIBUTIONS MADE BY THE STUDY TO EXISTING LITERATURE.}

\subsection{ORIGINALITY.}

Organizational change has so far been studied with particular reference to several areas, sectors, and industries including Railways (Tyrrall and Parker 2005, Laughlin 1991, Erakovic and Wilson 2005), Churches (Laughlin 1991), Telecoms (Erakovic and Wilson 2005), and privatization of state-owned enterprises (Dean, Carlisle and Baden-Fuller 1999, Springdal and Mador 2004). Similarly there are studies of organizational change with particular reference to and role of 'accounting/accountants' (Gray et al 1995), 'environmental accounting' (Larrinaga-Gonzalez et al 2001), and 'accounting/accountant' (Gray et al 1995), among others. Organizational Change in the microfinance sector has not so far been explored in detail, particularly in the context of Pakistan. This study was a modest attempt at filling this gap. This study makes an original contribution to the existing literature on microfinance and microfinance institutions, as a microfinance institution's adaptation and reorientation in response to a change in their external circumstances has not so far been studied in detail. Moreover, it provides an insight into the actual tangible and intangible changes one organization experienced while struggling to cope with its hostile external environment.

\subsection{COLONIZED REORIENTATION.}

As discussed above the evolution or transformation process suggested by the Laughlin (1991) model fully endorse the Aga Khan Rural Support Programme's transformation process. However, the categories of change - 'morphostatic reorientation' and 'colonization' suggested by the Laughlin (1991) Model do not seem to accommodate the process of the AKRSP's initial adaptation and reorientation in response to the changed environmental conditions. Since the external environmental disturbances caused change in not only its design archetypes but also in its sub-systems and interpretative schemes, the AKRSP's initial adaptation and reorientation to the changed external conditions should be categorized as a 'colonized reorientation', not a 'morphostatic reorientation' or 'colonization'.

Laughlin (1991) argues that in case of reorientation changes, the external disturbances will change the organization's design archetypes and sub-systems leaving the organization to keep its original interpretative schemes. The AKRSP's initial change cannot be categorized as 'morphostatic reorientation' in Laughlin's terminology because during this phase all three elements were adapted and reoriented to the changed environmental conditions. Whereas Laughlin's (1991) Model maintains that if the change is caused by an external environmental disturbance(s) then only the organization's design archetype and the sub-systems will reorient and the basic coherence, the interpretative schemes, will remain unaffected. According to the Model this happens in organizations during their reorientation phase. The empirical data collected for the study suggest that, during its initial reorientation phase, not only the AKRSP's design archetypes and the sub-systems were adapted and reoriented in response to the changed environmental but also its interpretative schemes. Thus, the Model does not cover the findings of this case study.

In case of a morphogenetic colonization, Laughlin maintains that the external disturbances cause change in all the three organizational elements - design archetype, interpretative schemes, and sub-systems. However, the model has conditionalized morphogenetic colonization to be a non-elected organizational change caused/forced by external environmental disturbances. This change then is promoted and inculcated in all organizational settings by a specific group of organizational members. It is not accepted and promoted by a general consensus of all the members. It forces other organizational members who do not 
support the group in their effort to change all organizational elements either to leave the organization or accept the change, whether willingly or unwillingly. This case study, on the other hand, suggests that the AKRSP's initial adaptation and reorientation was caused/forced by the changed environmental conditions where all the three elements - design archetype, interpretative schemes, and sub-systems were adapted (endorsed by Laughlin's model to this extent and referred to as morphogenetic colonization), but it was then openly accepted and promoted by a general consensus of all the organizational members (not imposed by a particular interest group on others) because all the members openly endorsed the fact that the long-term success and sustainability of the organization, under the changed environmental conditions, lies in its adaptation and gearing towards commercialism. Therefore the AKRSP's (Microfinance Division) initial adaptation and reorientation in response to external environmental disturbances could be called 'colonized reorientation' because none of the categories predicted by Laughlin's (1991) model for an organization's initial adaptation would cover such a change.

It is concluded, therefore, that an initial adaptation and reorientation in response to changed environmental conditions in all the three organizational elements - 'design archetypes', 'interpretative schemes', and 'sub-systems', openly accepted and promoted by a general consensus, not imposed by a particular interest group within the organization, may be categorized separately as 'colonized reorientation', particularly in the context of microfinance institutions and Pakistan. This should be allowed a room in the existing categories of organizational change in the Laughlin's model.

\section{CONCLUDING REMARKS.}

The substantive conclusions drawn about the Aga Khan Rural Support Programme's successful adaptation, reorientation, and subsequent transformation to a commercial setup will serve as a model in Pakistan to be followed by other microfinance institutions. The study carries significance in four ways: first, it will provide an insight into how MFIs can successfully adapt/adjust when faced with unavoidable external environmental disturbances, second, it will provide an insight into how MFIs can successfully adapt and reorient to unavoidable external environmental disturbances, third, the study will provide existing MFIs attempting such reconstruction with good lessons in their struggle for adaptation and reorientation to the changed environmental conditions, and fourth, it will provide new incoming MFIs with valuable insight into good policies and practices under the prevailing commercial approach in the sector.

The empirical data suggested that the Aga Khan Rural Support Programme's management was concerned for the welfare of the poor especially in the AKRSP's core areas of operations - the Northern Areas and Chitral - after the AKRSP's (Microfinance Division) transformation to the First Microfinance Bank Limited - an entirely commercial setup. Therefore, further studies are recommended to gauge the outreach of the AKRSP before and after its transformation, with two main objectives in mind: first, to ascertain success, in terms of outreach and impact on poverty, of the microfinance institution before and after its transformation to a purely commercial setup, and second, to throw some light on the real essence of microfinance under the 'welfarist' and the 'institutionist' approaches. Moreover, since this case study has focused on the AKRSP, a microfinance institution, in the special context of Pakistan, more studies in different national, social, and geographical contexts would be valuable to test the generalizability of its findings. Keeping in view the qualitative, in-depth nature, and regional focus of the study, I recognize that the findings may be viewed and interpreted accordingly. 


\section{REFERENCES}

ADB 2000, 'Finance for the Poor: Microfinance Development Strategy', Asian Development Bank, Manila.

Associated Press of Pakistan Corporation 2007, 'PM Approves Strategy to Expand Microfinance Outreach to 3 mln Households', Press Release, February 14

Baydas, M, Graham, D \& Valenzuela, L 1997, 'Commercial Banks in Microfinance: New Actors in the Microfinance World', Microenterprise Best Practices Project, USAID, Development Alternatives, Inc, Bethesda, Maryland.

Campos, N, Khan, F, \& Tessendorf, J 2004, 'From Substitution to Complementarity: Some Econometric Evidence on the Evolving NGO-State Relationship in Pakistan', The Journal of Developing Areas, vol. 37, no. 2, pp. 49-72. https://doi.org/10.1353/jda.2004.0021

CGAP 1996, 'Microcredit Interest Rates', Donor Brief No. 1, February, The World Bank' Washington DC.

CGAP 1997, 'The Challenge of Growth for Microfinance Institutions: The BancoSol Experience', Focus Note No. 6, March, The World Bank, Washington, DC.

CGAP 2006, 'Performance and Transparency: A Survey of Microfinance Institutions in South Asia', Microfinance Information Exchange, Inc, The World Bank, Washington DC.

Chang, FS, \& Wiebe, HA 1996, 'The Ideal Cultural Profile for Total Quality Management: A Competing Values Perspective', Engineering Management Journal, vol. 8, no. 2, pp. 19-26. https://doi.org/10.1080/10429247.1996.11414889

Chaves, RA, \& Gonzales-Vega, C 1996, 'The Design of Unsuccessful Rural Financial Intermediaries: Evidence from Indonesia', World Development, vol. 24, no. 1, pp. 65-78. https://doi.org/10.1016/0305-750X(95)00114-R

Conning, J 1999, 'Outreach, Sustainability and Leverage in Monitored and Peer-monitored Lending', Journal of Development Economics, vol. 60, pp. 51-77. https://doi.org/10.1016/S0304-3878(99)00036-X

Dean, A, Carlisle, Y \& Baden-Fuller, C 1999, 'Punctuated and Continuous Change: The UK Water Industry', British Journal of Management, vol. 10, pp. S3-S18. https://doi.org/10.5465/apbpp.1999.27592681

Dichter, TW 1996, 'Questioning the Future of NGOs in Microfinance', Journal of International Development, vol. 8, no. 2, pp. 259-269. https://doi.org/10.1002/(SICI)1099-1328(199603)8:2<259::AID-JID377>3.3.CO;2-Z

Edgcomb, EL \& Cawley, J 1994, 'The Process of Institutional Development: Assisting Small Enterprise Institutions Become More Effective', in M, Otero \& E, Rhyne (eds), The New World of Microenterprise Finance: Building Healthy Institutions for the Poor, Kumarian Press, West Harford, CT, pp. 76-93.

Erakovic, L \& Wilson, M 2005, 'Conditions of Radical Transformation in State-Owned Enterprises', British Journal of Management, vol. 16, pp. 293-313. https://doi.org/10.1111/j.1467-8551.2005.00467.X

Fernando, JL 2006, 'Microcredit and Empowerment of Women: Blurring the Boundary between Development and Capitalism', in JL Fernando (ed), Microfinance: Perils and Prospects, Routledge, New York, pp. 142.

Frankfurter, GM, \& McGoun, EG 1996, 'Toward Finance With Meaning the Methodology of Finance: What It Is and What It Can Be?’, JAI Press Inc, Greenwich. https://doi.org/10.3905/joi.1996.7

Fossey E, Harvey, C, McDermott, F, \& Davidson, L 2002, 'Understanding and Evaluating Qualitative Research', Australian and New Zealand Journal of Psychiatry, vol. 36, pp. 717-732. https://doi.org/10.1046/j.1440-1614.2002.01100.x

Gloekler, A, \& Seeley, J 2003, 'Gender and AKRSP - Mainstreamed or Sidelined?', Lessons in Development The AKRSP Experience, Aga Khan Rural Support Program, Islamabad, Pakistan.

Gonzalez-Vega, C \& Schreiner, M 1997, 'The challenge of growth for microfinance organizations: the case of Banco Solidario in Bolivia', in H, Schneider (Ed), Microfinance for the Poor?, Organization for Economic Co-operation and Development (OECD), Washington DC.

Gould, RM 1996, 'Getting from Strategy to Action: Processes for Continuous Change', Long Range Planning, vol. 29, no. 3, pp. 278-289. https://doi.org/10.1016/0024-6301(96)00018-0

Government of Pakistan 2003, 'Accelerating Economic Growth and Reducing Poverty: The Road Ahead', Poverty Reduction Strategy Paper, Ministry of Finance, Islamabad, Pakistan.

Gray, R, Walters, D, Bebbington, J \& Thompson, I 1995, 'The Greening of Enterprise: An Exploration of the (Non) Role of Environmental Accounting and Environmental Accountants in Organizational Change', 
Critical Perspectives on Accounting, vol. 6, pp. 211-239.

https://doi.org/10.1006/cpac.1995.1021

Hashemi, S, Sidney, RS \& Riley, P 1996, 'Rural credit programs and women's empowerment in Bangladesh', World Development, vol. 24, no. 4, pp. 635-653. https://doi.org/10.1016/0305-750X(95)00159-A

Hill, FM, \& Collins, LK 2000, 'A Descriptive and Analytical Model of Organisational Transformation', International Journal of Quality \& Reliability Management, vol. 17, no. 9, pp. 966-983. https://doi.org/10.1108/02656710010353876

Hopwood, AG 1987, 'The Archaeology of Accounting Systems', Accounting, Organizations and Society, vol. 12, no. 3, pp. 207-234. https://doi.org/10.1016/0361-3682(87)90038-9

Hulme, D, \& Mosley, P 1996a, 'Finance against poverty', vol. I, Routledge, London.

Hulme, D, \& Mosley, P 1996b, ‘Finance against poverty', vol. II, Routledge, London.

Hussein, M, \& Hussain, S 2003, 'The Impact of Microfinance on Poverty and Gender Equity: Approaches and Evidence from Pakistan', Pakistan Microfinance Network, Islamabad, Pakistan.

Hussein, M, \& Plateau, S 2003, 'Lessons in Development - The AKRSP Experience: Microfinance', Aga Khan Rural Support Programme, Islamabad, Pakistan.

IMF 2005, 'IMF Executive Board Concludes 2005 Article IV Consultation with Pakistan', Public Information Notice No. 05/157, Washington DC.

Khandker SR 1996, 'Grameen Bank: Impact, Costs, and Program Sustainability', Asian Development Review, vol. 14 , no. 1 , pp. 97-130.

Kuzel (1992), 'Sampling in Qualitative Inquiry', in BF, Crabtree \& WL, Miller (eds), Doing Qualitative Research, Sage Publications, Thousand Oaks, California, pp. 33-46.

Larrinaga-Gonzalez, C, Carrasco-Fenech, F, Caro-Gonzalez, FJ, Correa-Ruiz, C, \& Paez-Sandubete, JM 2001, 'The Role of Environmental Accounting in Organizational Change: An Exploration of Spanish Companies', Accounting, Auditing, \& Accountability Journal, vol. 14, no. 2, pp. 213-239. https://doi.org/10.1108/09513570110389323

Laughlin, R 1991, 'Environmental Disturbances and Organizational Transitions and Transformations: Some Alternative Models', Organization Studies, vol. 12, no. 2, pp. 209-232. https://doi.org/10.1177/017084069101200203

Layder, D 1993, 'New Strategies in Social Research', Polity Press, Cambridge.

Ledgerwood, J 1999, 'Microfinance Handbook: An Institutional and Financial Perspective', The World Bank, Washington, DC. https://doi.org/10.1596/978-0-8213-4306-7

Mason, J 2002, 'Qualitative Researching', $2^{\text {nd }}$ ed, Sage Publications, Thousand Oaks, London.

Mayer, RC, Davis, JH, \& Schoorman, FD 1995, 'An Integrative Model of Organizational Trust', Academy of Management Review, vol. 20, no. 33, pp. 709-734. https://doi.org/10.5465/amr.1995.9508080335

Morduch, J 1998, ‘The Microfinance Schism', Harvard University Press, Harvard University, Mimeograph.

Morduch, J 1999, ‘The Microfinance Promise', Journal of Economic Literature, vol. 37, pp. 1569-1614.

\section{https://doi.org/10.1257/jel.37.4.1569}

Nyborg, I \& Ali, J 2005, 'Exploring Nature, Wealth and Power Issues in Agriculture and Resource Management: A Case Study on the Aga Khan Rural Support Program, Northern Pakistan', Noragric Working Paper No. 39, Norwegian University of Life Sciences, Noragric.

Pakistan Microfinance Network 2004, 'Annual Report', Pakistan Microfinance Network Secretariat, Islamabad, Pakistan.

Poverty Reduction Strategy Paper 2006, ‘Annual Progress Report: 2005-2006’, Government of Pakistan, PRSP Secretariat - Finance Division, Islamabad.

Rehman, N 2002, 'Social Impacts and Constraints of Micro-Credit in the Alleviation of Poverty: A qualitative study of the Micro-Credit Programme OPP-Orangi Charitable Trust, Karachi', Retrieved March 2, 2006 from http://lnweb18.worldbank.org/SAR/sa.nsf/Attachments/Pakistan-PovertyAssessment/\$File/Pakistan-Poverty-Assessment.pdf.

Remenyi, J 1991, 'Where Credit is Due', ITP, London. https://doi.org/10.3362/9781780443843.000

Remenyi, J, \& Quinones Jr, B, Eds 2000, 'Microfinance and Poverty Alleviation: Case Studies from Asia and the Pacific', Pinter, London. 
Robinson, MS 2001, 'The Microfinance Revolution: Sustainable Finance for the Poor', The World Bank, Washington, DC.

https://doi.org/10.1596/0-8213-4524-9

Robinson, MS 2002, 'The Microfinance Revolution: Lessons from Indonesia', The World Bank, Washington, DC. https://doi.org/10.1596/0-8213-4953-8

Rogaly, B 1996, 'Micro-Finance Evangelism, 'Destitute Women', and the Hard Selling of a New Anti-Poverty Formula', Development in Practice, vol. 6, no. 2, pp. 100-112. https://doi.org/10.1080/0961452961000157654

Snow, D 1999, 'Microcredit: An Institutional Development Opportunity, International Journal of Economic Development, vol. 1, no. 1, pp. 65-79.

Social Policy and Development Centre 2006, 'SPDC Annual Review 2005-2006: Social Development in Pakistan, Trade Liberalization, Growth and Poverty’, Social Policy and Development Centre, Karachi.

Springdal, K, \& Mador, M 2004, 'Organizational Changes Resulting from the Privatization of State Enterprises', Public Money and Management, vol. 24, no. 1, pp. 69-80. https://doi.org/10.1111/j.1467-9302.2004.00395.x

Strauss, A, \& Corbin, J 1990, 'Basics of Qualitative Research: Grounded Theory Procedures and Techniques', Sage Publications, London.

The Aga Khan Rural Support Programme, 'Memorandum of Association', The Aga Khan Rural Support Program, Islamabad, Pakistan.

The Aga Khan Rural Support Programme, 'Minutes of the Various Meetings of the Board of Directors'.

The Aga Khan Rural Support Programme 1995, 'Contextual Study of the Northern Areas and Chitral', The Aga Khan Rural Support Programme, Islamabad, Pakistan.

The Aga Khan Rural Support Programme 1996, 'Policies and Procedures Manual', The AKRSP Core Office, Gilgit, Pakistan.

The Aga Khan Rural Support Programme 1997, ‘Annual Review’, The Aga Khan Rural Support Programme, Islamabad, Pakistan.

The Aga Khan Rural Support Programme 1999, 'Annual Review', The Aga Khan Rural Support Programme, Islamabad, Pakistan.

The Aga Khan Rural Support Programme 2000, 'Annual Review', The Aga Khan Rural Support Programme, Islamabad, Pakistan.

The Aga Khan Rural Support Programme 2001, 'Annual Review', The Aga Khan Rural Support Programme, Islamabad, Pakistan.

The First Microfinance Bank Limited 2003, ‘Annual Review’, The First Microfinance Bank Limited, Islamabad, Pakistan.

Trochim, WMK 1989, 'Outcome Pattern Matching and Program Theory', Evaluation and Program Planning, vol. 12, pp. 355-366. https://doi.org/10.1016/0149-7189(89)90052-9

Tyrrall, D, \& Parker, D 2005, 'The Fragmentation of a Railway: A study of Organizational Change', Journal of Management Studies, vol. 42, no. 3, pp. 507-537. https://doi.org/10.1111/j.1467-6486.2005.00507.x

USAID 2005, 'Economic Performance Assessment Report on Pakistan', August, USAID, Washington DC.

Woodside, AG, \& Wilson, EJ 2003, 'Case Study Research Methods for Theory Building', The Journal of Business and Industrial Marketing, vol. 18, no. 6, pp. 493-535.

World Bank 1995, 'The Aga Khan Rural Support Program in Pakistan: A Third Interim Evaluation', World Bank Operations Evaluation Study, World Bank, WashingtonDC.

World Bank 2002, ‘The Next Ascent: An Evaluation of the Aga Khan Rural Support Program, Pakistan', World Bank Operations Evaluation Department, Report No. 226, The World Bank, Washington DC.

Yaron, J 1994, 'What Makes Rural Finance Institutions Successful?', The World Bank Research Observer, vol. 9, no. 1, pp. 49-70. https://doi.org/10.1093/wbro/9.1.49

Yin, RK 1994, 'Case Study Research: Design and Methods', $2^{\text {nd }}$ Ed, Sage Publications, Thousand Oaks, California.

Yin, RK 1998, 'The Abridged Version of Case Study Research: Design and Method', in L, Bickman \& DJ, Rog (Eds), Handbook of Applied Social Research Methods, Sage Publications, Thousand Oaks, London. 
The Australasian Accounting Business \& Finance Journal, December, 2008. Khan: Paradigm Shift in the Microfinance Sector

Yin, RK 2003, 'Case Study Research: Design and Methods', Sage Publications, Thousand Oaks, London.

Zonabend F 1992, 'The Monograph in European Ethnology', Current Sociology, vol. 40, no. 1, pp. 49-60. https://doi.org/10.1177/001139292040001005 